\title{
Carbon balance of China constrained by CONTRAIL aircraft $\mathrm{CO}_{2}$ measurements
}

\author{
F. Jiang ${ }^{1,2}$, H. M. Wang ${ }^{1,2}$, J. M. Chen ${ }^{1,2}$, T. Machida ${ }^{3}$, L. X. Zhou ${ }^{4}$, W. M. Ju ${ }^{1,2}$, H. Matsueda ${ }^{5}$, and Y. Sawa ${ }^{5}$ \\ ${ }^{1}$ Jiangsu Provincial Key Laboratory of Geographic Information Science and Technology, Nanjing University, Nanjing, China \\ ${ }^{2}$ International Institute for Earth System Science, Nanjing University, Nanjing, China \\ ${ }^{3}$ National Institute for Environmental Studies, Tsukuba, Japan \\ ${ }^{4}$ Chinese Academy of Meteorological Sciences, China Meteorological Administration, Beijing, China \\ ${ }^{5}$ Geochemical Research Department, Meteorological Research Institute, Tsukuba, Japan
}

Correspondence to: H. M. Wang (wanghm@nju.edu.cn) and F. Jiang (jiangf@nju.edu.cn)

Received: 16 January 2014 - Published in Atmos. Chem. Phys. Discuss.: 21 March 2014

Revised: 13 August 2014 - Accepted: 25 August 2014 - Published: 23 September 2014

\begin{abstract}
Terrestrial carbon dioxide $\left(\mathrm{CO}_{2}\right)$ flux estimates in China using atmospheric inversion method are beset with considerable uncertainties because very few atmospheric $\mathrm{CO}_{2}$ concentration measurements are available. In order to improve these estimates, nested atmospheric $\mathrm{CO}_{2}$ inversion during 2002-2008 is performed in this study using passenger aircraft-based $\mathrm{CO}_{2}$ measurements over Eurasia from the Comprehensive Observation Network for Trace gases by Airliner (CONTRAIL) project. The inversion system includes 43 regions with a focus on China, and is based on the Bayesian synthesis approach and the TM5 transport model. The terrestrial ecosystem carbon flux modeled by the Boreal Ecosystems Productivity Simulator (BEPS) model and the ocean exchange simulated by the OPA-PISCES-T model are considered as the prior fluxes. The impacts of CONTRAIL $\mathrm{CO}_{2}$ data on inverted China terrestrial carbon fluxes are quantified, the improvement of the inverted fluxes after adding CONTRAIL $\mathrm{CO}_{2}$ data are rationed against climate factors and evaluated by comparing the simulated atmospheric $\mathrm{CO}_{2}$ concentrations with three independent surface $\mathrm{CO}_{2}$ measurements in China. Results show that with the addition of CONTRAIL $\mathrm{CO}_{2}$ data, the inverted carbon sink in China increases while those in South and Southeast Asia decrease. Meanwhile, the posterior uncertainties over these regions are all reduced (2-12\%). CONTRAIL $\mathrm{CO}_{2}$ data also have a large effect on the inter-annual variation of carbon sinks in China, leading to a better correlation between the carbon sink and the annual mean climate factors. Evaluations against the $\mathrm{CO}_{2}$ measurements at three sites in China also
\end{abstract}

show that the CONTRAIL $\mathrm{CO}_{2}$ measurements may have improved the inversion results.

\section{Introduction}

Carbon dioxide $\left(\mathrm{CO}_{2}\right)$ and other greenhouse gases emitted from human activities are the main cause of global warming (IPCC, 2007). Terrestrial ecosystems play a very important role in regulating the atmospheric $\mathrm{CO}_{2}$ concentration. According to the evidence from atmosphere observations, Le Quéré et al. (2009) estimated that the mean $\mathrm{CO}_{2}$ uptake rate of the global terrestrial ecosystem is $2.6 \pm 0.7 \mathrm{Pg} \mathrm{C} \mathrm{yr}^{-1}$ for 1990-2000, which offsets $40 \%$ of the global fossil fuel carbon emissions. Pacala et al. (2001) found that North American terrestrial ecosystems sequestered $30-50 \%$ of its industrial $\mathrm{CO}_{2}$ emissions in the 1980s. China has a vast land area of $960 \times 10^{6}$ ha, and nearly $80 \%$ of the land areas are covered with various types of vegetation including forest $(16.5 \%)$, grass $(34.8 \%)$, shrubs $(18.5 \%)$, croplands (11.2\%), and other types (Fang et al., 2007). Using the methods of bottom-up (inventory survey and process-based ecosystem model) and top-down (atmospheric inversion) approaches, many studies have been conducted during the past decade to estimate China's terrestrial ecosystem carbon sinks (e.g., Cao et al., 2003; Fang et al., 2007; Piao et al., 2009; Tian et al., 2011; Jiang et al., 2013). Fang et al. (2007) estimated the land sinks in China could offset $20.0-26.8 \%$ of its industrial carbon emissions. However, there are still large 
gaps of land sink derived using bottom-up and top-down methods (Piao et al., 2009). One of the main reasons may be attributed to the lack of enough $\mathrm{CO}_{2}$ concentration observations. Jiang et al. (2013) pointed out that due to lack of sufficient observations, most regions of the country have a low regional and annual uncertainty reduction percentage $(<10 \%)$ by way of atmospheric inversion, especially for South and Southwest China, and the overall uncertainty reduction is relatively lower compared with North America and Europe.

The lack of surface measurements can partially be compensated for by aircraft measurements in the free troposphere. Many vertical profiles of $\mathrm{CO}_{2}$ have been obtained over Europe and North America using research aircraft (Crevoisier et al., 2010; Xueref-Remy et al., 2011). Compared with research aircrafts, passenger aircraft $\mathrm{CO}_{2}$ measurements are done at a much lower cost and could cover larger areas. Presently, there are two well-known $\mathrm{CO}_{2}$ measurement projects using passenger aircrafts, the Civil Aircraft for the Regular Investigation of the atmosphere Based on an Instrument Container (CARIBIC) project (Brenninkmeijer et al., 2007; Schuck et al., 2009) and the Comprehensive Observation Network for Trace gases by Airliner (CONTRAIL) project (Machida et al., 2008; Matsueda et al., 2008). CARIBIC measures atmospheric $\mathrm{CO}_{2}$ by flask sampling between Germany and destinations in Europe, Africa, North and South America, and Asia with four flights per month, while CONTRAIL measures $\mathrm{CO}_{2}$ continuously between Japan and Europe, Australia, South and Southeast Asia, and North America. Patra et al. (2011) performed an inversion study based on CARIBIC data and evaluated the results against CONTRAIL data. With the CONTRAIL measurements, Niwa et al. (2012) conducted an inverse modeling study with a focus on tropical terrestrial regions. Their results showed that CONTRAIL data have a large impact on the inversion results.

In this study, a China-focused atmospheric inversion is conducted using CONTRAIL measurements over Eurasia. The inversion system and CONTRAIL data used are first described, followed by a presentation and discussion of the impact of CONTRAL data on inverted carbon fluxes and posterior uncertainties in China and its surrounding areas.

\section{Method and data}

\subsection{Inversion setting}

In this study, a nested inversion system (Jiang et al., 2013) based on Bayesian synthesis inversion method (Rayner et al., 1999; Enting and Mansbridge, 1989) is used to improve the estimations of monthly $\mathrm{CO}_{2}$ sources and sinks as well as their uncertainties. The global surface is separated into 43 regions based on the 22 TransCom large regions (e.g., Gurney et al., 2003; Baker et al., 2006), with 13 small regions in China (Fig. 2). The partition scheme for the 13 small regions is mainly based on land cover types, i.e., forest (five regions), crop (four regions), grass (three regions), and desert (one region).

A monthly transport operator for the 43 regions and forward transport simulations for carbon emissions from fossil fuel and biomass burning are calculated using a global two-way nested transport model TM5 (Krol et al., 2005). The fossil fuel inventory is from the Miller Carbon Tracker fossil fuel emission field (CarbonTracker, 2010), which is constructed based on CDIAC 2007 (Boden et al., 2010) and EDGAR 4 databases (Olivier and Berdowski, 2001). The biomass-burning inventory is from the Global Fire Emissions Database version 3 (GFEDv3) (van der Werf et al., 2010). Except for sources and sinks, the key processes of $\mathrm{CO}_{2}$ in the atmosphere are horizontal and vertical transport and diffusion. In the TM5 model, the horizontal transport is based on the slopes advection scheme (Russel and Lerner, 1981), the convection is parameterized according to Tiedtke (1989), and the vertical diffusion near-surface layer and in the free troposphere are parameterized using the schemes of Holtslag and Moeng (1991) and Louis (1979), respectively. An evaluation showed that TM5 performs very well on vertical and horizontal transport (Stephens et al., 2007). In this study, TM5 model is driven by the European Centre for MediumRange Weather Forecasts (ECMWF) outputs, and is run at a horizontal resolution of $3^{\circ} \times 2^{\circ}$ around the world without nesting a high-resolution domain and a vertical structure of 25 layers, with the model top at about $1 \mathrm{hPa}$.

Hourly terrestrial ecosystem carbon exchanges simulated by the Boreal Ecosystems Productivity Simulator (BEPS) model (Chen et al., 1999; Ju et al., 2006) and daily carbon fluxes across the air-water interface calculated by the OPAPISCES-T model (Buitenhuis et al., 2006) are considered as prior fluxes. Before being used in the inversion, both of these two types of fluxes are averaged monthly. In addition, the monthly terrestrial carbon fluxes of each grid are neutralized annually. The $1 \sigma$ uncertainties for the prior fluxes over the global land and ocean surfaces are assumed to be 2.0 and $0.67 \mathrm{PgC} \mathrm{yr}^{-1}$, respectively, which are the same as those used in Deng and Chen (2011). That is because we use the same land and ocean prior fluxes with Deng and Chen (2011). Deng and Chen (2011) did a $\chi^{2}$ test for their selections, and results indicated that these uncertainties are reasonable. The uncertainty on the land is spatially distributed based on the annual net primary productivity (NPP) distribution simulated by BEPS, while the one on the ocean is distributed according to the area of each ocean region. The monthly uncertainties for the terrestrial regions are assigned according to the variations of monthly NPP, while the ones for oceanic regions are assumed to be even. We do not consider the relationship between different regions. Hence, a diagonal matrix for error variances is used. This is because the global land is separated into a series of regions mainly according to land cover type, and we assume that the 

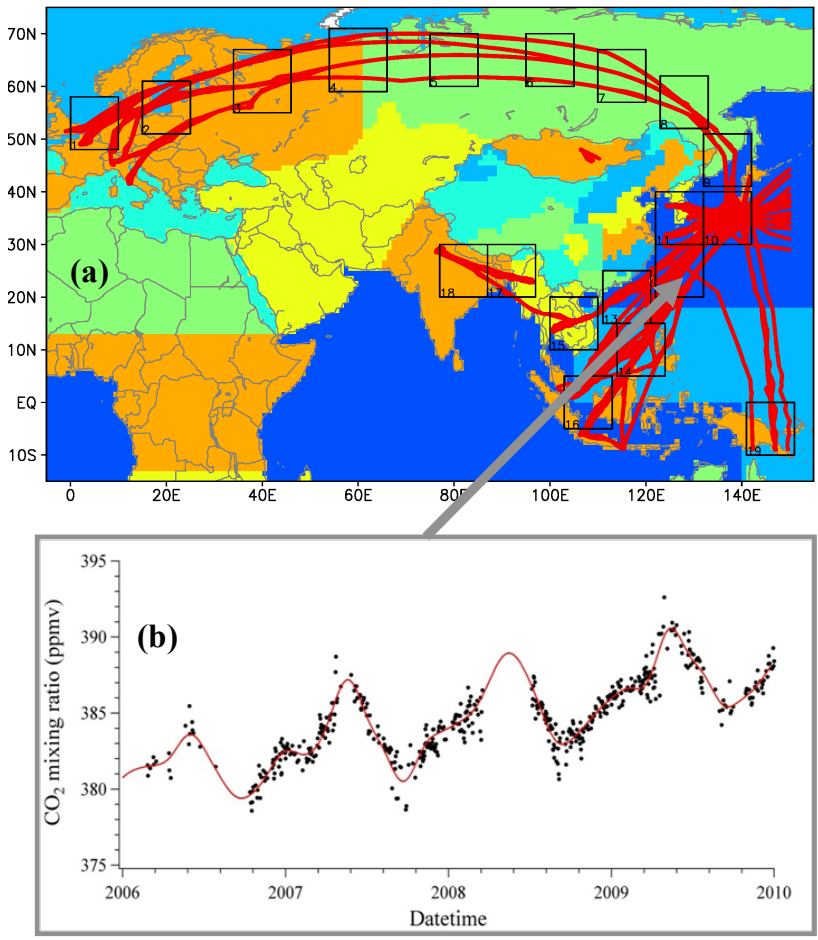

Figure 1. A map of CONTRAIL measurements; (a) the CONTRAIL measurement locations (red dots), black rectangles represent the area partitions of the measurements of level flights, shaded represent different inversion regions over Eurasia; (b) time series of the measurements over East China Sea, black line indicates a curve fitted to the daily $\mathrm{CO}_{2}$.

relationship of the fluxes of different land cover types could be negligible.

A total of 130 sites of $\mathrm{CO}_{2}$ observations from GLOBALVIEW-CO 2010 data set (GLOBALVIEW-CO ${ }_{2}$, 2010) are adopted, including 54 flask observations, seven continuous measurements, five tower sites, six ship sites, and 58 aircraft sites. The locations of the GLOBALVIEW (GV) $\mathrm{CO}_{2}$ observations can be found in Fig. 2. The model-data mismatch error in ppm (parts per million) is defined using the following function, which is similar to those used by Peters et al. (2005) and Deng and Chen (2011).

$R=\sigma_{\text {const }}^{2}+\mathrm{GVSD}^{2}$,

where GVSD reflects the observation error; it is the standard deviation of the residual distribution in the average monthly variability (var) file of GLOBALVIEW- $\mathrm{CO}_{2} 2010$. The constant portion $\sigma_{\text {const }}$ reflects the simulation error, which varies with station type, that is, because the transport models generally have different performances at different observation stations. Except for some difficult stations, the observation sites are divided into five categories. The categories (respective value in ppm) are Antarctic sites/oceanic flask and continuous sites (0.30), ship and tower sites (1.0), mountain sites (1.5), aircraft samples (0.5), and land flask/continuous sites

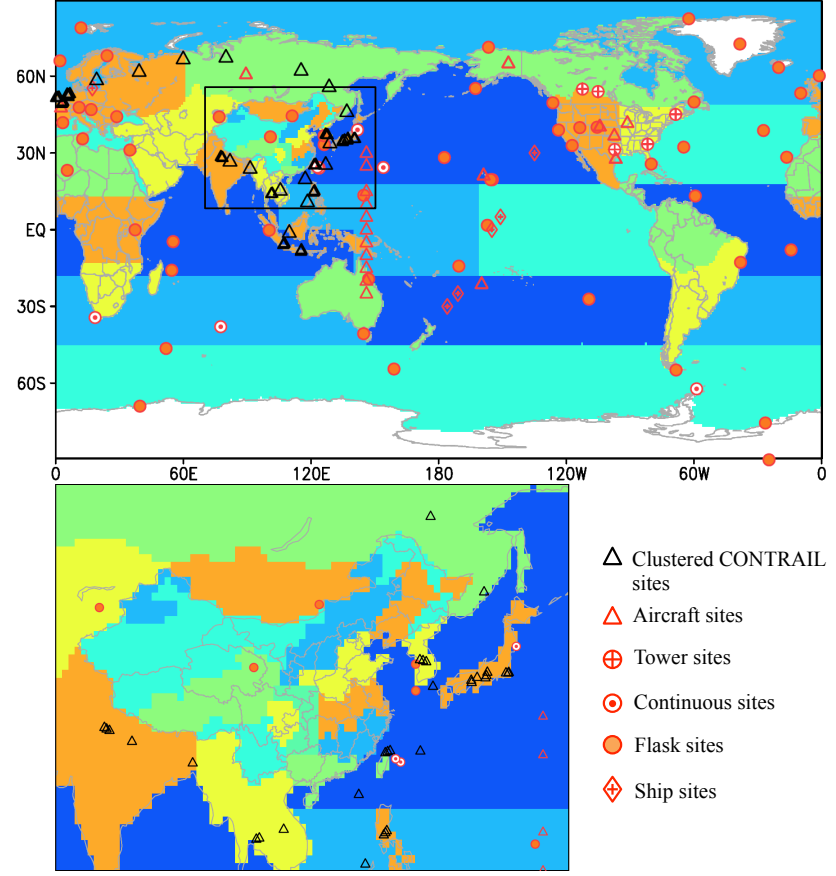

Figure 2. An inversion scheme: 21 regions in Asia (13 regions in China) and 22 regions for the rest of the globe. Locations of $184 \mathrm{CO}_{2}$ observational sites are also indicated, including 130 sites from $\mathrm{GV}$ data set (54 flask sites, seven continuous sites, five tower sites, six ship sites, 58 aircraft sites) and 54 sites from CONTRAIL aircraft measurements (bold ones include three vertical sites at 2000-4000, 4000-6000, 6000-8000 m for ascending and descending flights data and thin ones include one site at $8000-12000 \mathrm{~m}$ for level flights data).

(0.75). The value of 3.5 is used for the difficult sites (e.g., abp_01D0, bkt_01D0).

\subsection{CONTRAIL aircraft $\mathrm{CO}_{2}$ measurements}

The CONTRAIL project measures $\mathrm{CO}_{2}$ concentrations using continuous measurement equipment on passenger aircrafts (Machida et al., 2008; Matsueda et al., 2008). Calibrations and evaluations have shown that the accuracy of $\mathrm{CON}$ TRAIL data compares well with the $\mathrm{GV} \mathrm{CO}_{2}$ data (Machida et al., 2011). In this study, aircraft $\mathrm{CO}_{2}$ measurements over Eurasia during November 2005 to December 2009 are used. The measurements between Japan and Europe, Korea, Taiwan, South Asia, and Southeast Asia are shown in Fig. 1a. In order to use the continuous observations in the inversion system, the measurements are divided into 87 sites, including 19 level flight sites $(\sim 10 \mathrm{~km}$, Fig. 1a) and 68 vertical sites. Following Niwa et al. (2012), each vertical measurement profile is divided into five layers: 0-1000, 1000-2000, 2000-4000, 4000-6000, and 6000-8000 m. The flight altitude higher than $8000 \mathrm{~m}$ is considered as level flight. For the level flight sites, first, we define 19 regions each with a $10 \times 10$ degrees size according to the flight routes (Fig. 1a); 
then all the observation records with altitude higher than $8000 \mathrm{~m}$ located in one region are averaged to get the concentration of that site, and its location is determined by averaging the location of all observation records as well. It should be noted that the $10^{\circ} \times 10^{\circ}$ boxes are only applied to the level flight. Before being used in the inversion, (1) daily mean data for each site are smoothed (Fig. 1b) using the same technique as Masarie and Tans (1995) and then averaged to a monthly mean value; (2) the sites with samples shorter than 6 months are excluded; (3) the variations of the monthly $\mathrm{CO}_{2}$ concentrations for each site are carefully checked, and we find that in the boundary layer (below $2000 \mathrm{~m}$ ), the concentrations at most sites are highly affected by local emissions, probably emitted by aircraft frequently ascending and descending, hence, only data measured above $2000 \mathrm{~m}$ are used. Niwa et al. (2012) also only used the free tropospheric (above $625 \mathrm{hpa}$ ) data. In addition, in previous studies (Sawa et al., 2008; Niwa et al., 2012), the $\mathrm{CO}_{2}$ records in the stratosphere were filtered out, because the seasonal variation of $\mathrm{CO}_{2}$ in stratosphere is quite different from that in troposphere. However, in this study, we do not distinguish whether the $\mathrm{CO}_{2}$ records are in stratosphere or in troposphere. We have checked the monthly observed and forward simulated $\mathrm{CO}_{2}$ concentrations at the level flight sites and thought that the influences of stratospheric $\mathrm{CO}_{2}$ could be neglectful in our inversion system. Consequently, 54 CONTRAIL $\mathrm{CO}_{2}$ sites are used in the inversion (Fig. 2). The model-data mismatch errors of the CONTRAIL data are calculated using the same method as those of the GV data. The observation error (GVSD) is the standard deviation of the residual after smoothing, and for the item of $\sigma_{\text {const }}$, considering the large range $\left(10^{\circ} \times 10^{\circ}\right)$ of the level flight sites and the thick layer of the vertical sites, we use a constant of $0.75 \mathrm{ppm}$, which is larger than that of GV aircraft samples (0.5 ppm).

\section{$2.3 \mathrm{CO}_{2}$ measurements in China}

In this study, $\mathrm{CO}_{2}$ concentrations measured during July 2006-December 2009 at three Chinese sites are used to evaluate forward simulation results. The three sites were all established by Chinese Academy of Meteorological Sciences (CAMS), China Meteorological Administration (CMA), with the names Longfengshan (LFS), Shangdianzi (SDZ) and LinAn (LAN). LFS, SDZ and LAN are located in Northeast China, North China, and East China, respectively (Fig. 3). The weekly flask measurements of these stations are sampled and analyzed using the recommended methods of the Global Atmosphere Watch Programme of World Meteorological Organization (WMO/GAW), and the results are comparable to that of the Earth System Research Laboratory in National Oceanic and Atmospheric Administration (NOAA/ESRL). For more detailed information about these observations, please refer to Liu et al. (2009).

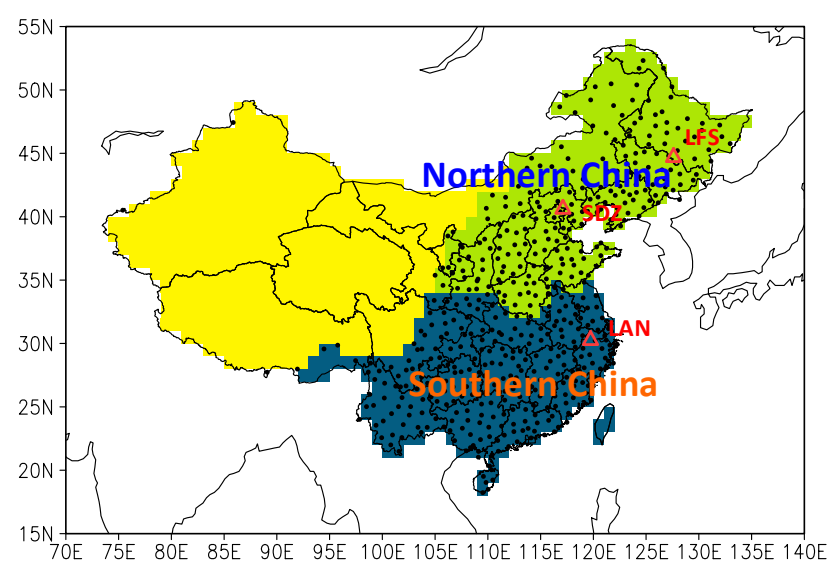

Figure 3. Locations of observations (black point: meteorological data locations; red triangle: $\mathrm{CO}_{2}$ observation sites in China, which are used for evaluation in this study).

\section{Results and discussions}

\subsection{Impact on inter-annual variations}

Two inversion experiments are conducted from 2000 to 2009; the first (Case GV) run with only $\mathrm{GV} \mathrm{CO}_{2}$ included and the second run with CONTRAIL $\mathrm{CO}_{2}$ data added (Case GVCT). For each experiment, the first two years are considered to be the spin-up period, and the last year is the spin-down time; therefore, the analysis period in this study is from 2002 to 2008.

Figure 4 shows the inter-annual variations (IAVs) of the inverted land sinks (excluding biomass burning emissions, the same thereafter) and the posterior uncertainties of the two experiments in China. When only $\mathrm{GV} \mathrm{CO}_{2}$ is used, the IAVs show a less negative trend, with the strongest land sink occurring in 2002, and the weakest sink in 2008. When CONTRAIL $\mathrm{CO}_{2}$ is added after November 2005, changes of inverted sinks occur after 2005, with the largest change in 2007, compared to Case GV. The CONTRAIL $\mathrm{CO}_{2}$ also has an impact on the posterior uncertainties from 2005 to 2008, especially in 2007 and 2008. The posterior uncertainties in 2007 and 2008 are reduced from around 0.195 to $0.183 \mathrm{PgC} \mathrm{yr}^{-1}$, with a reduction rate of $6 \%$.

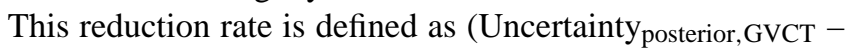
Uncertainty $\left._{\text {posterior,GV }}\right) \times 100 /$ Uncertainty $_{\text {posterior,GV }}$ (same thereafter). In our other study (Jiang et al., 2013), we added $\mathrm{CO}_{2}$ measurements of the three Chinese sites in the same inversion system, and results showed that the posterior uncertainties were reduced from around 0.195 to $0.173 \mathrm{Pg} \mathrm{C} \mathrm{yr}^{-1}$ $(\sim 11 \%)$ in 2007 and 2008. Hence, we think that this uncertainty reduction caused by adding the CONTRAIL data is reasonable in comparison with the uncertainty reduction caused by adding the three Chinese sites and in consideration of the fact that there are no CONTRAIL data in China: all data were measured in the downwind or upwind 


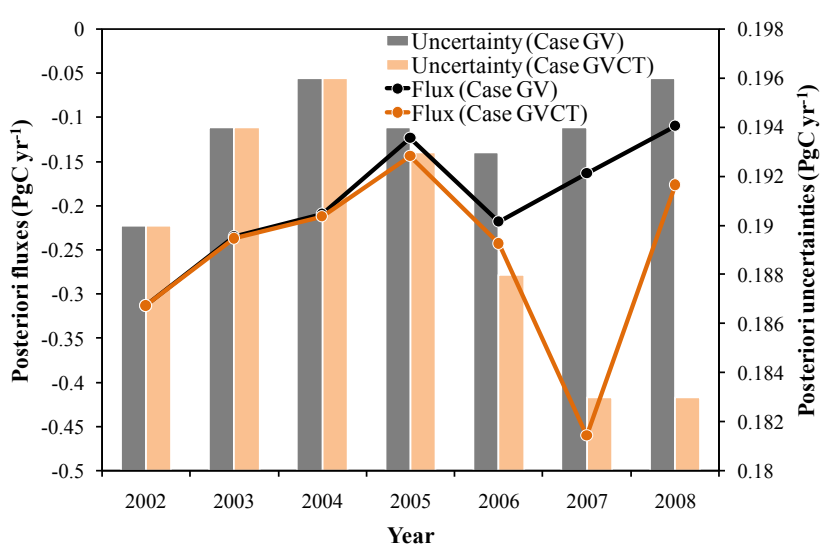

Figure 4. Impact on inter-annual variations of inverted carbon flux and posterior uncertainty in China.

of China and only data above the boundary layer are used in the inversion. Overall, when the CONTRAIL $\mathrm{CO}_{2}$ data are added, the inverted carbon sink in China increases by $0.05 \mathrm{PgC} \mathrm{yr}^{-1}(30 \%)$, the posterior uncertainty is reduced by $0.0043 \mathrm{PgC} \mathrm{yr}^{-1}(2.2 \%)$, and the mean carbon sink in China is $-0.25 \pm 0.19 \mathrm{Pg} \mathrm{C} \mathrm{yr}^{-1}$ for 2002 to 2008 .

Climate factors, such as temperature, precipitation and radiation, could affect plant growth (Zhu et al., 2007; Myoung et al., 2013), thereby the IAVs of land sinks (Ciais et al., 2005). Generally, a warmer condition advances vegetation growth for most regions in middle and high latitudes of the Northern Hemisphere $(\mathrm{NH})$, including the crops in Europe and US, and the forests in central Siberia, western Canada and northeastern China (Myoung et al., 2013). Zhu et al. (2007) also showed that in northern China, the plant growth was temperature limited. Usually, more vigorous vegetation growth corresponds to more carbon uptake. Studies on the relationships between the net ecosystem exchange (NEE) measured by eddy covariance equipment and the environmental factors confirm that the IAVs of annual mean air temperature is significantly related to the ones of NEE in the forest regions in middle and high latitudes of the NH. Yuan et al. (2009) pointed out that air temperature was the primary environmental factor that determined the IAV of NEE in deciduous broadleaf forest across the North American sites, and NEE was positively correlated with the mean annual air temperature; Dunn et al. (2007) found that in central Manitoba, Canada, warmer annual temperatures were associated with increased net uptake, while annual precipitation did not explain any of the variability in NEE. Nevertheless, in low latitudes of the $\mathrm{NH}$, for example, southern China, the NEE may be related to solar radiation and precipitation. Zhu et al. (2007) reported that in southern China, the plant growth was radiation limited. Usually, more radiation corresponds to less cloud cover, so as to less precipitation (Fig. 5a). Based on eddy covariance measurements in two forest sites in southern China, Yan et al. (2013) found that the greater annual NEE
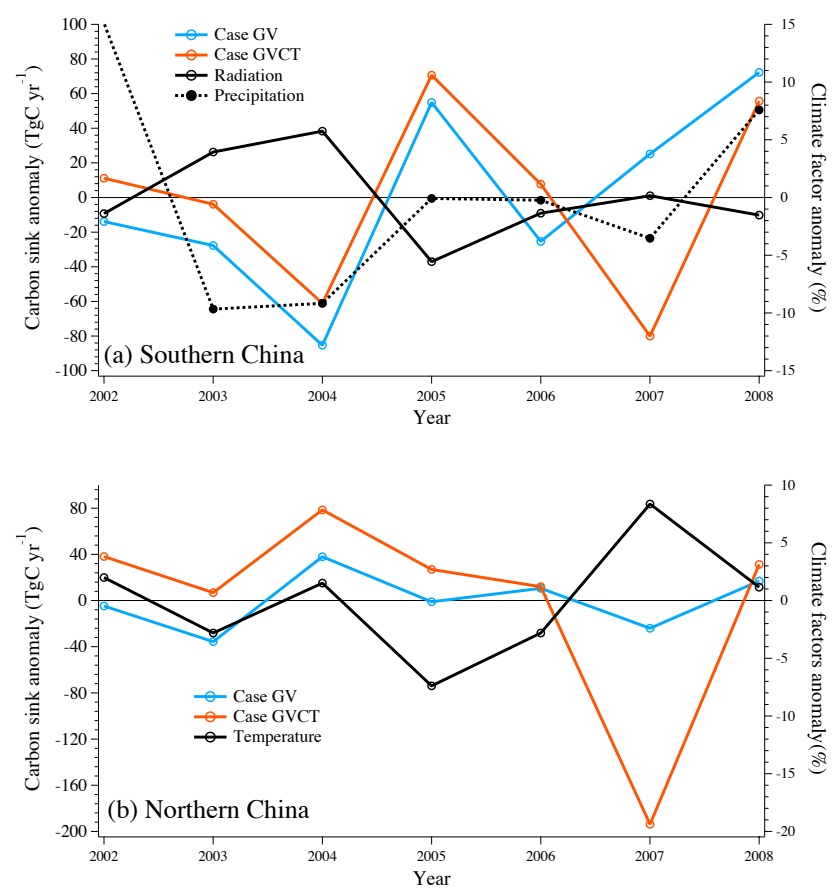

Figure 5. Inter-annual variations of the posterior fluxes and climate factors in (a) southern China and (b) northern China.

(more uptake) usually occurred in the dry years and smaller annual NEE in the rainy years for the both forests. Hence, in order to study whether the impact of CONTRAIL data is reasonable, it should be useful to check the relationship between inter-annual variations of climate factors and land sinks in different regions of China. Because the changes of posterior fluxes mainly occur in southern China and northern China (see Sect. 3.2), only these two regions are investigated. Monthly climate data of 484 stations obtained from CMA during the study period are used for the analysis, in which 269 stations are located in southern China, and the others are located in northern China (Fig. 3). Figure 5 shows the IAVs of annual mean climate factor anomalies and land sink anomalies in southern China and northern China. It could be found that in southern China, the changes caused by CONTRAIL data lead to a better correlation between the fluxes and radiation as well as precipitation, and in northern China, the changes also make the fluxes better correlated with the temperature. These relationships are consistent with the previous findings, indicating that the IAVs of posterior fluxes in China by additional constraint of CONTRAIL $\mathrm{CO}_{2}$ data could be more reasonable.

\subsection{Impact on spatial pattern}

As shown in Sect. 3.1, CONTRAIL $\mathrm{CO}_{2}$ has a large impact on the inverted carbon fluxes and a certain impact on the uncertainties during the 2006-2008 period. Furthermore, the impacts of CONTRAIL $\mathrm{CO}_{2}$ on the spatial patterns 

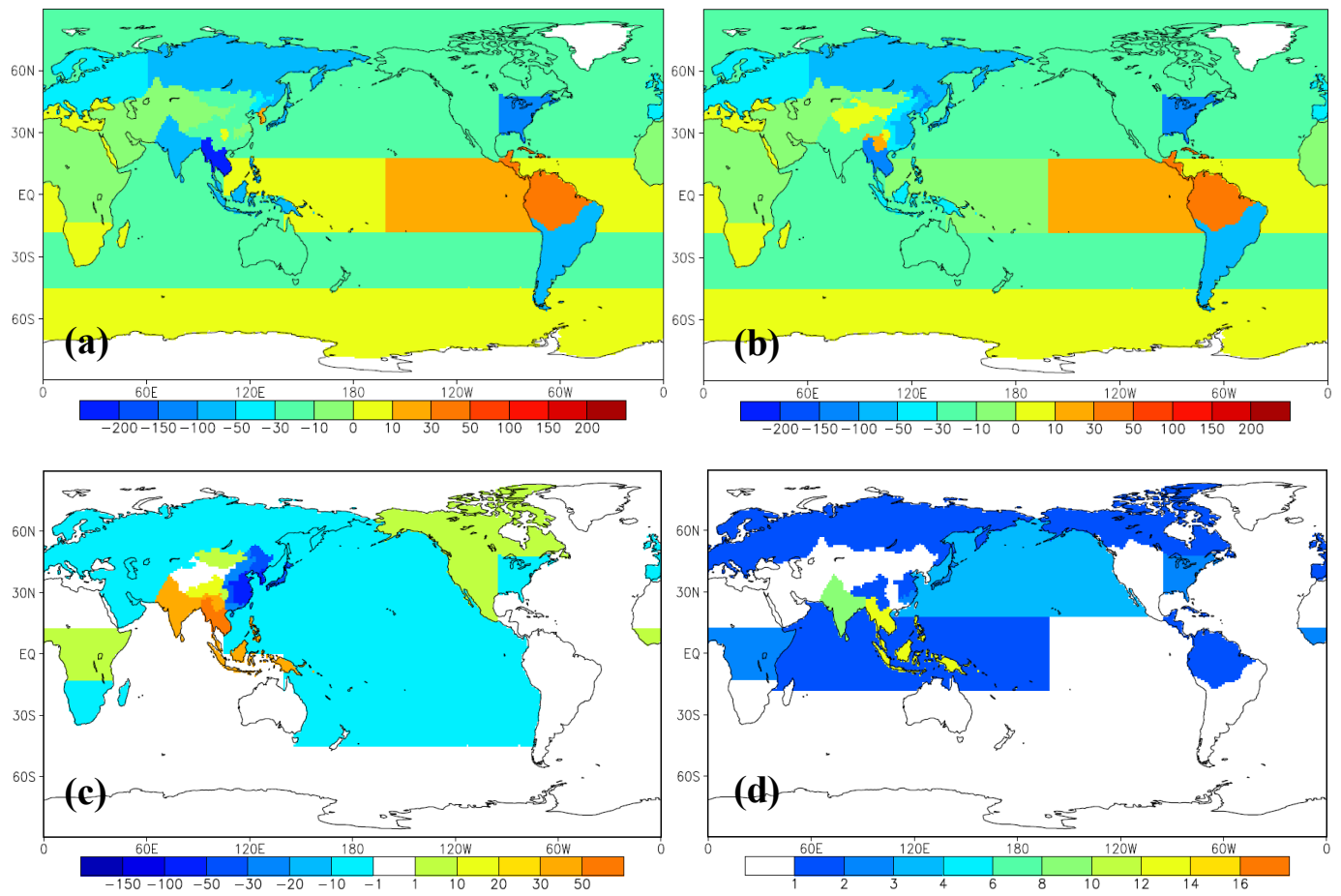

Figure 6. Inverted global carbon flux for (a) Case $\mathrm{GV}$, unit: $\mathrm{gCm}^{-2} \mathrm{yr}^{-1}$; (b) Case GVCT, unit: $\mathrm{g} \mathrm{Cm}^{-2} \mathrm{yr}^{-1}$; and impact of CONTRAIL $\mathrm{CO}_{2}$ on (c) the inverted carbon fluxes, Case GVCT-Case GV, unit: $\mathrm{g} \mathrm{C} \mathrm{m}^{-2} \mathrm{yr}^{-1}$ and (d) posterior uncertainties, (Case GV-Case GVCT) $\times 100 /$ Case GV, unit: \%; averaged for 2006 to 2008 .

of the inverted global carbon fluxes and uncertainties for 2006-2008 are shown in Fig. 6. For Case GV, most of the land regions are found to be carbon sinks (Fig. 6a), with strong sinks (> $50 \mathrm{~g} \mathrm{C} \mathrm{m}^{-2} \mathrm{yr}^{-1}$ ) occurring in boreal Asia, South and Southeast Asia, the eastern US, and southern South America (S.A.), while tropical America and Southern Africa appear as carbon sources. Most Chinese regions appear as weak carbon sinks $\left(<30 \mathrm{~g} \mathrm{C} \mathrm{m}^{-2} \mathrm{yr}^{-1}\right)$. Comparing Case GVCT with the Case GV, the carbon sinks decrease in South and Southeast Asia, tropical Africa, boreal and western temperate North America, and Southwest China, with the most significant decrease happening in Southeast Asia ( $>50 \mathrm{~g} \mathrm{C} \mathrm{m}^{-2} \mathrm{yr}^{-1}$ ). The carbon sinks increase in Europe, boreal and western Asia, eastern temperate North America, eastern China, southern Africa, and most of the Pacific, with the most notable increase in eastern China. It should be noted that though only CONTRAIL $\mathrm{CO}_{2}$ data over Eurasia are used in this study, its impacts are global. Meanwhile, posterior uncertainties over most of the Northern Hemisphere and tropical regions are reduced, with the most significant reduction occurring in South and Southeast Asia $(\sim 10 \%)$. In China, the uncertainty reduction in all regions is smaller than $5 \%$, with largest reductions in East and Southwest China.

Compared with results from Niwa et al. (2012) for the same time period, the decrease of land sink in Southeast Asia, increases of land sinks in Europe, boreal Asia, eastern temperate North America, and southern Africa, and the reduc- tions of posterior uncertainties in South and Southeast Asia are consistent. However, in South Asia and eastern China, although large effects of CONTRAIL $\mathrm{CO}_{2}$ data on land sinks were also derived in Niwa et al. (2012), the impacts are opposite. Moreover, the magnitude of the effects on the inverted land fluxes and associated uncertainties are much smaller than those in Niwa et al. (2012). In order to gain insight on the causes of the differences between this study and Niwa et al. (2012), mean monthly prior and posterior fluxes of Case GV and Case GVCT in China, South Asia, and Southeast Asia (including Indo-China Peninsula and tropical Asia) during 2006-2008 are compared in Fig. 7. In China, there are large differences in the prior fluxes. The seasonal amplitude of Niwa's fluxes (simulated using CASA model) is much larger than that (simulated using BEPS model) of this study. After being constrained by GV and CONTRAIL $\mathrm{CO}_{2}$ data, the posterior fluxes from this study and Niwa et al. (2012) tend to be close to each other: the land sinks during growing season increase in this study, while they decrease in Niwa et al. (2012), and the strongest sinks are very similar in magnitude. However, the flux estimated in this study turns from source to sink in May, reaching the strongest in July, while that estimated in Niwa et al. (2012) turns from source to sink in July, reaching the strongest in August. This delay leads to a relatively large divergence in the inverted annual carbon sink ( -0.29 vs. $\left.0.25 \mathrm{Pg} \mathrm{C} \mathrm{yr}^{-1}\right)$. In contrast, in South Asia, the seasonal amplitude of the prior fluxes from Niwa 

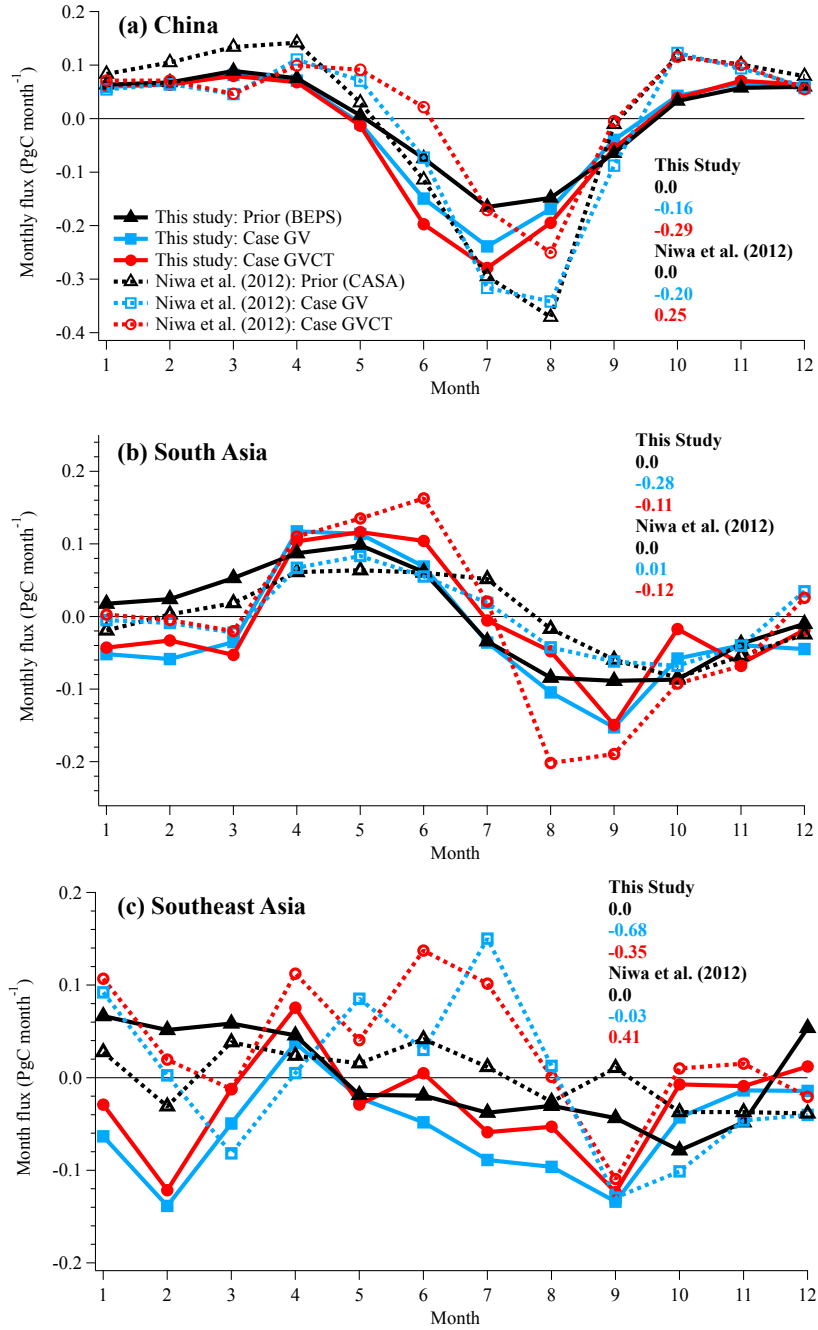

Figure 7. Mean monthly fluxes in (a) China, (b) South Asia and (c) Southeast Asia during 2006-2008 (Case GV: only constrained by $\mathrm{GV} \mathrm{CO}_{2}$; Case GVCT: constrained by both $\mathrm{GV} \mathrm{CO}_{2}$ and $\mathrm{CON}-$ TRAIL $\mathrm{CO}_{2}$ ).

et al. (2012) is smaller than that of this study. When only being constrained with $\mathrm{GV} \mathrm{CO}_{2}$ data, the land sinks during the growing season obviously increase in this study, while little change happens with the results of Niwa et al. (2012). After CONTRAIL $\mathrm{CO}_{2}$ data are added, the sinks during the growing season decrease, and the sources during non-growing season increase in this study, leading to a decrease in the annual land sink; while in Niwa et al. (2012), the land sources increase significantly during the non-growing season, and the land sinks during the growing increase remarkably as well. The annual land sinks in South Asia from these two studies are very close. In Southeast Asia, there are also significant differences in the prior fluxes: compared with the results of Niwa et al. (2012), there are much higher carbon sinks from May to October, and higher sources from December to April in this study. When only being constrained with $\mathrm{GV} \mathrm{CO}_{2}$ data, except in October and November, more carbon is absorbed in all months in this study, especially in February and September; while in Niwa et al. (2012), the land sinks increase in March, September, and October, and in the other months, the land sources increase. The annual land sink increases from 0.0 to $-0.68 \mathrm{Pg} \mathrm{C} \mathrm{yr}^{-1}$ in this study, while little change occurs in Niwa et al. (2012). This difference may be partly due to the use of the Bukit Koto Tabang (BKT) station in Indonesia and the CONTRAIL-ASE observations between Australia and Japan included in the GLOBALVIEW data set in this study (Fig. 2), which were not used in Niwa et al. (2012). After the CONTRAIL $\mathrm{CO}_{2}$ data are added, the carbon sinks decrease in all months in this study, and they decrease in most months in Niwa et al. (2012) as well. The monthly variations of the posterior fluxes between this study and Niwa et al. (2012) are similar to a certain extent, especially from September to December. However, from January to August, the carbon sources in Niwa et al. (2012) are significantly higher than that of this study, especially in January, February, June, and July. Overall, the uses of different prior fluxes and amount of GV observations may result in these different effects of CONTRAIL $\mathrm{CO}_{2}$ data. However, the posterior fluxes from these two studies tend to be close to each other after being constrained with CONTRAIL $\mathrm{CO}_{2}$ data.

The statistics show that with the further constraint of CONTRAIL $\mathrm{CO}_{2}$ data, the carbon sink in China increases

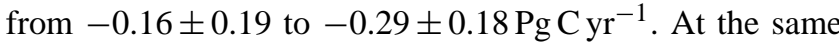
time, the land sinks of Southeast Asia and South Asia decrease from $-0.68 \pm 0.34$ to $-0.28 \pm 0.32$ and $-0.35 \pm 0.30$ to $-0.11 \pm 0.30 \mathrm{Pg} \mathrm{Cyr}^{-1}$, respectively. When CONTRAIL data are added, the land sink in China is close to the inversion result of $-0.35 \mathrm{PgC} \mathrm{yr}^{-1}$ stated in Jiang et al. (2013) for the same period, which was derived by adding three additional China $\mathrm{CO}_{2}$ observation stations. The land sink obtained for South Asia, $-0.11 \pm 0.30 \mathrm{Pg} \mathrm{C} \mathrm{yr}^{-1}$, agrees well with the $-0.104 \pm 0.15 \mathrm{Pg} \mathrm{Cyr}^{-1}$ result of Patra et al. (2013) for 2007-2008 period. Southeast Asia is one of the most forested regions in the world. Its land sink should be dominated by forest. Pan et al. (2011) estimated that here the forest carbon flux from 2000 to 2007 was $-0.12 \mathrm{Pg} \mathrm{C} \mathrm{yr}^{-1}$. Carbon emission from biomass burning is $0.30 \mathrm{Pg} \mathrm{C} \mathrm{yr}^{-1}$ in this region from GFEDv3, so, the net carbon flux, excluding fossil fuel emissions, is $-0.05 \mathrm{Pg} \mathrm{C} \mathrm{yr}^{-1}(-0.35+0.30=$ $-0.05 \mathrm{Pg} \mathrm{C} \mathrm{yr}^{-1}$ ), which is comparable to the results of Pan et al. (2011). The main reason of the significant changes in South and Southeast Asia is that there are very few $\mathrm{CO}_{2}$ measurements in the GV data set in these regions (Fig. 2), so there is an insufficient observational constraint, leading to large uncertainties in the inverted carbon fluxes. The addition of CONTRAIL data reduces uncertainty by markedly increasing observations in these regions. Despite the fact that most CONTRAIL $\mathrm{CO}_{2}$ measurements are in the middle and upper troposphere, due to strong tropical convection, the resulting observational constraints are still relatively strong, thus decreasing land sinks in these regions. Niwa et al. (2012) 


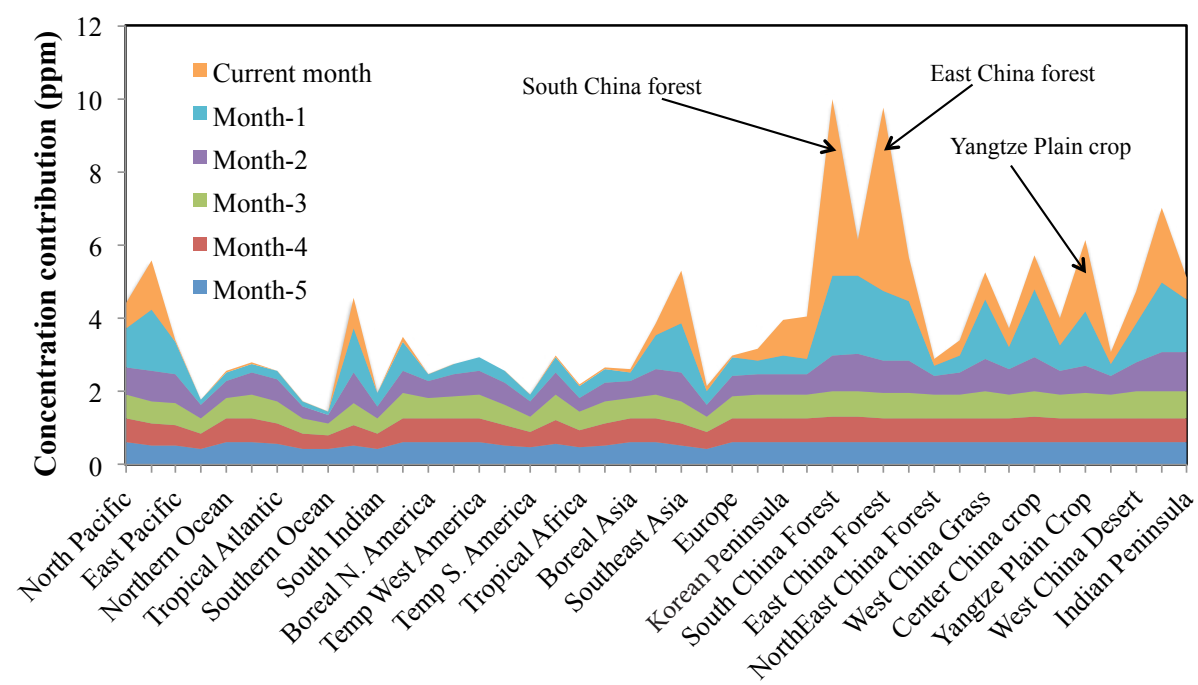

Figure 8. Contributions from emissions of different regions in July 2007 and the previous five months $\left(1 \mathrm{Pg} \mathrm{C} \mathrm{month}^{-1}\right.$ region $\left.^{-1}\right)$ to the $\mathrm{CO}_{2}$ concentration in July 2007 at 2000-4000 m over Taipei airport (TPE).

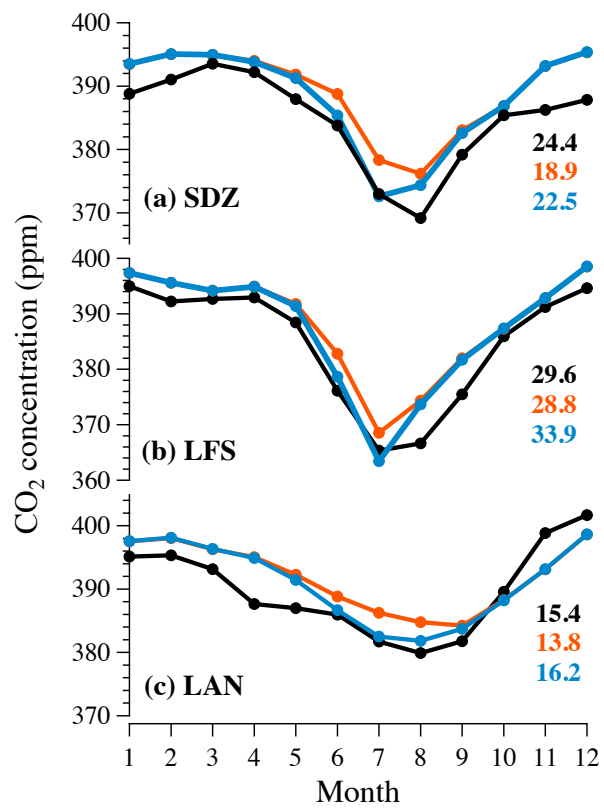

Figure 9. Simulated and observed monthly $\mathrm{CO}_{2}$ concentrations at three China stations, the black lines represent the observations, the orange lines represent the simulations from the land fluxes constrained with $\mathrm{GV} \mathrm{CO}_{2}$ only, the blue lines represent the simulations from the land fluxes constrained by additional CONTRAIL $\mathrm{CO}_{2}$, and the numbers represent the concentration amplitude between wintertime and summertime.

have detailed the mechanisms of CONTRAIL $\mathrm{CO}_{2}$ data impacts on the fluxes. The large changes in Eastern China could be explained with that there are many CONTRAIL $\mathrm{CO}_{2}$ measurements over East China Sea, Korea, and Japan, which are mostly downwind of China, so CONTRAIL $\mathrm{CO}_{2}$ over these regions could directly sense carbon fluxes in eastern China to a certain extent. Figure 8 shows contributions from emissions in different regions of the globe at a current month (July 2007) and for the previous five months (1 Pg carbon emitted from each region at one month) to the $\mathrm{CO}_{2}$ concentration in July 2007 at 2000-4000 m height over Taipei airport (TPE). There are strong contributions from the emissions of eastern China (South China, East China forest, and Yangtze plain) at the current month (July 2007). Therefore, CONTRAIL $\mathrm{CO}_{2}$ data could affect the inversion results in China.

\subsection{Evaluation against $\mathrm{CO}_{2}$ measurements in China}

We further use the $\mathrm{CO}_{2}$ concentration measured at the three Chinese observation sites, i.e., LFS, SDZ, and LAN, to evaluate the forward simulation results using the TM5 model from the posterior fluxes. The weekly measurements are smoothed and extrapolated to obtain monthly values, using the same technique as $\mathrm{GV} \mathrm{CO}$ data set (Masarie and Tans, 1995). The simulations are conducted from 2000 to 2009, with initial concentration of $368.75 \mathrm{ppm}$ (Ed Dlugokencky and Pieter Tans, NOAA/ESRL; www.esrl.noaa.gov/gmd/ccgg/trends/). Since the impact of CONTRAIL $\mathrm{CO}_{2}$ is the largest in 2007, the simulation results in 2007 are evaluated using the $\mathrm{CO}_{2}$ concentration measurements (Fig. 9). Obviously, the simulated $\mathrm{CO}_{2}$ concentrations using the posterior fluxes constrained by CONTRAIL data are much closer to the observations during the summertime at all three sites. The mean biases between the simulations and observations at LAN, LFS, and SDZ are reduced from 2.13, 4.39, and $3.62 \mathrm{ppm}$ to $1.28,3.40$, and $2.74 \mathrm{ppm}$, respectively. Moreover, the seasonal amplitude of $\mathrm{CO}_{2}$ concentration between wintertime and summertime may better reflect the seasonal variations in land ecosystem sources and sinks in the upwind areas of 
(a)
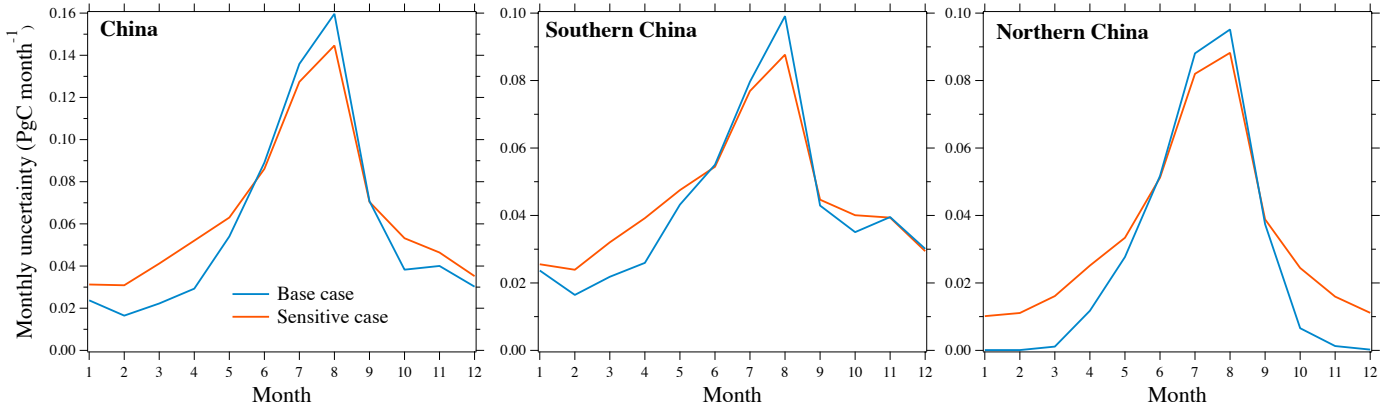

(b)
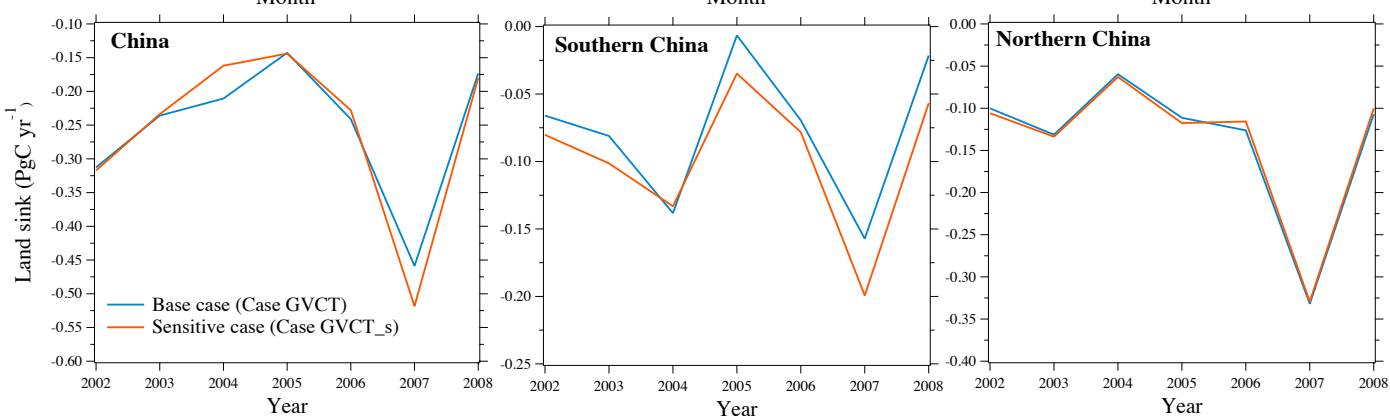

(c)
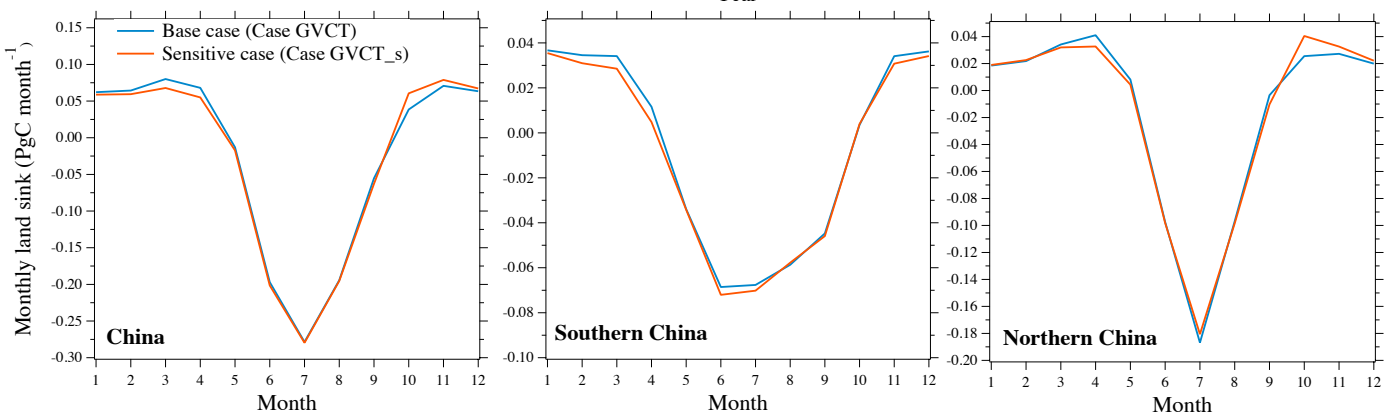

(d)
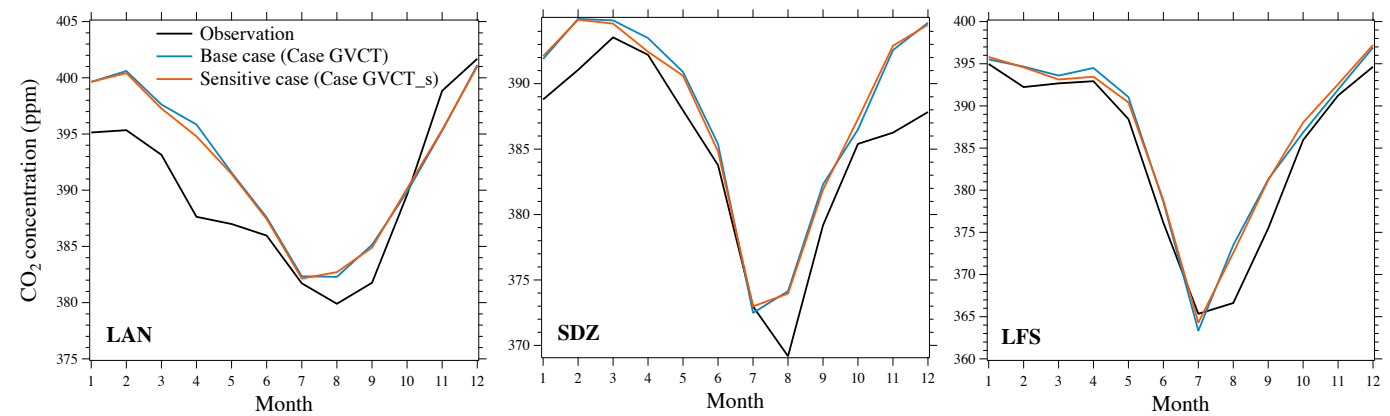

Figure 10. The sensitivity of the influence of (a) monthly prior flux uncertainty on the inverted carbon sinks over China, including (b) the inter-annual variations and (c) the monthly variations, as well as (d) the simulated $\mathrm{CO}_{2}$ concentrations in 2007 at the three Chinese sites using the inverted carbon fluxes.

the stations. Except at SDZ, simulated concentration amplitude using posterior fluxes constrained by CONTRAIL data is also much closer to the observations (Fig. 9) than those without the CONTRAIL constraint. Therefore, CONTRAIL data may have helped improve the inversion results for China at a certain extent.

\subsection{Sensitivity analysis}

It could be found that the changes caused by CONTRAIL data over China, including the inverted monthly carbon sinks (Fig. 7a) and the concentrations simulated using the inverted fluxes (Fig. 9), mainly occur in the warm seasons. This phenomenon may be attributed to the inversion setup for the monthly prior fluxes uncertainties, i.e., the monthly prior errors for the terrestrial regions are assigned according to the 
variations of monthly NPP (Sect. 2.1), which lead to the prior errors in the cold seasons that are very small, especially in the high latitude areas. Therefore, we conduct two sensitivity experiments, namely, Case GV_s and Case GVCT_s, in which both variations of monthly NPP and soil respiration (RESP) are considered when we assign the month prior errors.

As shown in Fig. 10a, in China, after both considered the NPP and RESP, the monthly prior uncertainties in summer are reduced, while those in cold seasons are enhanced, especially in northern China. These changes cause the land sink to decrease in Northeast China and West China and increase in the other regions of China (not shown). As an aggregate, in southern China, the land sink increases in most years, but the IAVs are the same as before; in northern China, basically, there is no change. Seasonally, in southern China, the land sinks increase in all months, and in northern China, they increase in spring and decrease in autumn. As a whole in China, though the land sink decreases in 2004 and increases in 2007 at a certain level, and little change occurs in the other years, the IAVs are basically the same as before. Seasonally, more carbon uptake occurs in spring and less happens in autumn (Fig. 10b, c), leading to the decrease in simulated concentrations spring and more closer observations at all three sites (Fig. 10d). However, the gaps between the simulated and the observed concentrations during the cold seasons are still large, especially at LAN and SDZ. Since LAN is close to Hangzhou City and SDZ is close to Beijing City, these large gaps may be related to the model resolution. Overall, the mean land sinks during 2002-2008 in China are $0.187 \pm 0.20$ and $0.255 \pm 0.20 \mathrm{Pg} \mathrm{C} \mathrm{yr}^{-1}$ for Case GV_s and Case GVCT_s, respectively, which are almost the same as the values of $-0.194 \pm 0.19$ and $-0.253 \pm 0.19 \mathrm{Pg} \mathrm{C} \mathrm{yr}^{-1}$ for Case GV and Case GVCT, indicating that the different settings of monthly prior errors have little impact on the inverted carbon budget in China.

\section{Summary and conclusions}

In this study, CONTRAIL Aircraft $\mathrm{CO}_{2}$ measurements over Eurasia are used to constrain the inversion except for the GV $\mathrm{CO}_{2}$ data in a nested atmospheric inversion system with the focus on China during 2002-2008. The CONTRAIL $\mathrm{CO}_{2}$ measurements are grouped into 87 sites, and 54 of the sites are then added into the inversion system. The impact of the CONTRAL data on the inverted carbon fluxes and posterior uncertainties in China and its surrounding areas are quantified. Results show that when the CONTRAIL $\mathrm{CO}_{2}$ data are added, the inverted carbon sink in China increases, and that in South and Southeast Asia decreases. The changes in South and Southeast Asia make the inverted carbon sinks more comparable with previous studies. CONTRAIL $\mathrm{CO}_{2}$ data also make a large impact on the inverted inter-annual variation of carbon sinks in China, with the largest change in 2007. This change makes the carbon sink in northern China better correlated with the annual mean air temperature and that in southern China better correlated with the solar radiation and precipitation. Moreover, we use the $\mathrm{CO}_{2}$ data measured at three China observation sites to evaluate the forward simulation results using the TM5 model based on the posterior fluxes. Results show that the large change of the land sink in China in 2007 has made the simulated concentrations in better agreement with the observations at three sites that are not used in the inversion. Finally, it is interesting to note that more $\mathrm{CO}_{2}$ measurements in or around China added to the inversion, the more it lead to an increase in the inverted sinks in China.

Acknowledgements. This work is supported by the National Key Basic Research Development Program of China (grant no: 2010CB950704, 2010CB950601 and 2010CB833503), National Natural Science Foundation of China (grant no: 41271211 and 41175116), and the Priority Academic Development Program of Jiangsu Higher Education Institutions. The authors also wish to thank D. Scott Munro for critical reading of the manuscript, Yosuke Niwa for providing inversion data of Niwa et al. (2012), Wouter peters and Feng Deng for valuable technical assistance.

Edited by: C. Gerbig

\section{References}

Baker, D. F., Law, R. M., Gurney, K. R., Rayner, P., Peylin, P., Denning, A. S., Bousquet, P., Bruhwiler, L., Chen, Y. H., Ciais, P., Fung, I. Y., Heimann, M., John, J., Maki, T., Maksyutov, S., Masarie, K., Prather, M., Pak, B., Taguchi, S., and Zhu, Z.: TransCom 3 inversion intercomparison: Impact of transport model errors on the interannual variability of regional $\mathrm{CO}_{2}$ fluxes, Global Biogeochem. Cy., 20, 1988-2003, 2006.

Boden, T. A., Marland, G., and Andres, R. J.: Global, regional, and national fossil-fuel $\mathrm{CO}_{2}$ emissions, Carbon Dioxide Information Analysis Center, Oak Ridge National Laboratory, US Department of Energy, Oak Ridge, Tenn., USA, doi:10.3334/CDIAC/00001_V2010, 2010.

Brenninkmeijer, C. A. M., Crutzen, P., Boumard, F., Dauer, T., Dix, B., Ebinghaus, R., Filippi, D., Fischer, H., Franke, H., Frieß, U., Heintzenberg, J., Helleis, F., Hermann, M., Kock, H. H., Koeppel, C., Lelieveld, J., Leuenberger, M., Martinsson, B. G., Miemczyk, S., Moret, H. P., Nguyen, H. N., Nyfeler, P., Oram, D., O'Sullivan, D., Penkett, S., Platt, U., Pupek, M., Ramonet, M., Randa, B., Reichelt, M., Rhee, T. S., Rohwer, J., Rosenfeld, K., Scharffe, D., Schlager, H., Schumann, U., Slemr, F., Sprung, D., Stock, P., Thaler, R., Valentino, F., van Velthoven, P., Waibel, A., Wandel, A., Waschitschek, K., Wiedensohler, A., Xueref-Remy, I., Zahn, A., Zech, U., and Ziereis, H.: Civil Aircraft for the regular investigation of the atmosphere based on an instrumented container: The new CARIBIC system, Atmos. Chem. Phys., 7, 4953-4976, doi:10.5194/acp-7-4953-2007, 2007.

Buitenhuis, E., Le Quéré, C., Aumont, O., Beaugrand, G., Bunker, A., Hirst, A., Ikeda, T., O’Brien, T., Piontkovski, S., and Straile, D.: Biogeochemical fluxes through mesozooplankton, Global 
Biogeochem. Cy., 20, GB2003, doi:10.1029/2005GB002511, 2006.

Cao, M. K., Prince, S. D., Li, K. R., Tao, B., Small, J., and Shao, X. M.: Response of terrestrial carbon uptake to climate interannual variability in China, Glob. Change Biol., 9, 536-546, 2003.

CarbonTraker: Fossil Fuel Module, http://www.esrl.noaa.gov/gmd/ ccgg/carbontracker/CT2010/documentation_ff.html\#ct_doc, last access: 12 March 2014, 2010.

Chen, J. M., Liu, J., Cihlar, J., and Goulden, M. L.: Daily canopy photosynthesis model through temporal and spatial scaling for remote sensing applications, Ecol. Model., 124, 99-119, 1999.

Ciais, P., Reichstein, M., Viovy, N., Granier, A., Ogee, J., Allard, V., Aubinet, M., Buchmann, N., Bernhofer, C., Carrara, A., Chevallier, F., De Noblet, N., Friend, A. D., Friedlingstein, P., Grunwald, T., Heinesch, B., Keronen, P., Knohl, A., Krinner, G., Loustau, D., Manca, G., Matteucci, G., Miglietta, F., Ourcival, J. M., Papale, D., Pilegaard, K., Rambal, S., Seufert, G., Soussana, J. F., Sanz, M. J., Schulze, E. D., Vesala, T., and Valentini, R.: Europewide reduction in primary productivity caused by the heat and drought in 2003, Nature, 437, 529-533, 2005.

Crevoisier, C., Sweeney, C., Gloor, M., Sarmiento, J. L., and Tans, P. P.: Regional US carbon sinks from three-dimensional atmospheric $\mathrm{CO}_{2}$ sampling, Proc. Natl. Acad. Sci. USA, 107, 1834818353, doi:10.1073/pnas.0900062107, 2010.

Deng, F. and Chen, J. M.: Recent global $\mathrm{CO}_{2}$ flux inferred from atmospheric $\mathrm{CO}_{2}$ observations and its regional analyses, Biogeosciences, 8, 3263-3281, doi:10.5194/bg-8-3263-2011, 2011.

Dunn, A. L., Barford, C. C., Wofsy, S. C., Goulden, M. L., and Daube, B. C.: A long-term record of carbon exchange in a boreal black spruce forest: means, responses to interannual variability, and decadal trends, Glob. Change Biol., 13, 577-590, doi:10.1111/j.1365-2486.2006.01221.x, 2007.

Enting, I. G. and Mansbridge, J. V.: Seasonal sources and sinks of atmospheric $\mathrm{CO}_{2}$ : direct inversion of filtered data, Tellus $\mathrm{B}, 41$, 111-126, 1989.

Fang, J. Y., Guo, Z. D., Piao, S. L., and Chen, A. P.: Terrestrial vegetation carbon sinks in China, 1981-2000, Science in China (D-Earth Science), 50, 1341-1350, 2007.

GLOBALVIEW-CO $\mathrm{CO}_{2}$ : Cooperative Atmospheric Data Integration Project - Carbon Dioxide, NOAA ESRL, Boulder, Colorado, available at: http://www.esrl.noaa.gov/gmd/ccgg/ globalview/ (last access: 12 March 2014), 2010.

Gurney, K. R., Law, R. M., Denning, A. S., Rayner, P. J., Baker, D., Bousquet, P., Bruhwiler, L., Chen, Y. H., Ciais, P., Fan, S. M., Fung, I. Y., Gloor, M., Heimann, M., Higuchi, K., John, J., Kowalczyk, E., Maki, T., Maksyutov, S., Peylin, P., Prather, M., Pak, B. C., Sarmiento, J., Taguchi, S., Takahashi, T., and Yuen, C. W.: TransCom $3 \mathrm{CO}_{2}$ inversion intercomparison: 1 . Annual mean control results and sensitivity to transport and prior flux information, Tellus, 55B, 555-579, 2003.

Holtslag, A. A. M. and Moeng, C.-H.: Eddy diffusivity and countergradient transport in the convective atmospheric boundary layer, J. Atmos. Sci., 48, 1690-1698, 1991.

Intergovernmental Panel on Climate Change (IPCC), I.S.A.: The Physical Science Basis of Climate Change: changes in Atmospheric Constituents and in Radiative Forcing, Cambridge University Press, New York, 2007.

Jiang, F., Wang, H. W., Chen, J. M., Zhou, L. X., Ju, W. M., Ding, A. J., Liu, L. X., and Peters, W.: Nested atmospheric inversion for the terrestrial carbon sources and sinks in China, Biogeosciences, 10, 5311-5324, doi:10.5194/bg-10-5311-2013, 2013.

Ju, W. M., Chen, J. M., Black, T. A., Barr, A. G., Liu, J., and Chen, B. Z.: Modelling multi-year coupled carbon and water fluxes in a boreal aspen forest, Agr. Forest Meteor., 140, 136-151, 2006.

Krol, M., Houweling, S., Bregman, B., van den Broek, M., Segers, A., van Velthoven, P., Peters, W., Dentener, F., and Bergamaschi, P.: The two-way nested global chemistry-transport zoom model TM5: algorithm and applications, Atmos. Chem. Phys., 5, 417432, doi:10.5194/acp-5-417-2005, 2005.

Le Quéré, C., Raupach, M. R., Canadell, J. G., Marland, G., Bopp, L., Ciais, P., Conway, T. J., Doney, S. C., Feely, R., Foster, P., Friedlingstein, P., Gurney, K., Houghton, R. A., House, J. I., Huntingford, C., Levy, P. E., Lomas, M. R., Majkut, J., Metzl, N., Ometto, J. P., Peters, G. P., Prentice, I. C., Randerson, J. T., Running, S. W., Sarmiento, J. L., Schuster, U., Sitch, S., Takahashi, T., Viovy, N., van der Werf, G. R., and Woodward, F. I.: Trends in the sources and sinks of carbon dioxide, Nat. Geosci., 2, 831-836, doi:10.1038/ngeo689, 2009.

Liu, L. X., Zhou, L. X., Zhang, X. C., Wen, M., Zhang, F., Yao, B., and Fang, S. X.: The characteristics of atmospheric $\mathrm{CO}_{2}$ concentration variation of four national background stations in China, Sci. China Ser. D-Earth Sci., 52, 1857-1863, doi:10.1007/s11430-009-0143-7, 2009.

Louis, J. F.: A parametric model of vertical eddy fluxes in the atmosphere, Bound. Lay. Meteorol., 17, 187-202, 1979.

Machida, T., Matsueda, H., Sawa, Y., Nakagawa, Y., Hirotani, K., Kondo, N., Goto, K., Nakazawa, T., Ishikawa, K., and Ogawa T. Worldwide measurements of atmospheric $\mathrm{CO}_{2}$ and other trace gas species using commercial airlines, J. Atmos. Ocean. Tech., 25, 1744-1754, doi:10.1175/2008JTECHA1082.1, 2008.

Machida, T., Tohjima, Y., Katsumata, K., and Mukai, H.: A new $\mathrm{CO}_{2}$ calibration scale based on gravimetric one-step dilution cylinders in National Institute for Environmental Studies-NIES $09 \mathrm{CO}_{2}$ scale, GAW Rep. 194, 114-119, World Meteorol. Organ., Geneva, Switzerland, 2011.

Masarie, K. A. and Tans, P. P.: Extension and integration of atmospheric carbon dioxide data into a globally consistent measurement record, J. Geophys. Res., 100, 11593-11610, 610, doi:10.1029/95JD00859, 1995.

Matsueda, H., Machida, T., Sawa, Y., Nakagawa, Y., Hirotani, K., Ikeda, H., Kondo, N., and Goto, K.: Evaluation of atmospheric $\mathrm{CO}_{2}$ measurements from new flask air sampling of JAL airliner observations, Pap. Meteorol. Geophys., 59, 1-17, doi:10.2467/mripapers.59.1, 2008.

Myoung, B., Choi, Y. S., Hong, S., and Park, S. K.: Inter- and intraannual variability of vegetation in the Northern Hemisphere and its association with precursory meteorological factors, Global Biogeochem. Cy., 27, 31-42, doi:10.1002/gbc.20017, 2013.

Niwa, Y., Machida, T., Sawa, Y., Matsueda, H., Schuck, T. J., Brenninkmeijer, C. A. M., Imasu, R., and Satoh, M.: Imposing strong constraints on tropical terrestrial $\mathrm{CO}_{2}$ fluxes using passenger aircraft based measurements, J. Geophys. Res., 117, D11303, doi:10.1029/2012JD017474, 2012.

Olivier, J. G. J. and Berdowski, J. J. M.: Global emissions sources and sinks, in: Berdowski, edited by: Guicherit, J. R. and Heij, B. J., The Climate System, 33-78, A. A. Balkema Publishers/Swets \& Zeitlinger Publishers, Lisse, The Netherlands, ISBN 905809 $2550,2001$. 
Pacala, S. W., Hurtt, G. C., Baker, D., Peylin, P., Houghton, R. A., Birdsey, R. A., Heath, L., Sundquist, E. T., Stallard, R. F., Ciais, P., Moorcroft, P., Caspersen, J. P., Shevliakova, E., Moore, B., Kohlmaier, G., Holland, E., Gloor, M., Harmon, M. E., Fan, S.M., Sarmiento, J. L., Goodale, C. L., Schimel, D., and Field, C. B.: Consistent land- and atmosphere-based US carbon sink estimates, Science, 292, 2316-2320, 2001.

Pan, Y., Birdsey, R. A., Fang, J., Houghton, R., Kauppi, P. E., Kurz, W. A., Phillips, O. L., Shvidenko, A., Lewis, S. L., Canadell, J. G., Ciais, P., Jackson, R. B., Pacala, S., McGuire, A. D., Piao, S., Rautiainen, A., Sitch, S., and Hayes, D.: A large and persistent carbon sink in the world's forests, Science, 333, 988-993, doi:10.1126/science.1201609, 2011.

Patra, P. K., Niwa, Y., Schuck, T. J., Brenninkmeijer, C. A. M., Machida, T., Matsueda, H., and Sawa, Y.: Carbon balance of South Asia constrained by passenger aircraft $\mathrm{CO}_{2}$ measurements, Atmos. Chem. Phys., 11, 4163-4175, doi:10.5194/acp11-4163-2011, 2011.

Patra, P. K., Canadell, J. G., Houghton, R. A., Piao, S. L., Oh, N.-H., Ciais, P., Manjunath, K. R., Chhabra, A., Wang, T., Bhattacharya, T., Bousquet, P., Hartman, J., Ito, A., Mayorga, E., Niwa, Y., Raymond, P. A., Sarma, V. V. S. S., and Lasco, R.: The carbon budget of South Asia, Biogeosciences, 10, 513-527, doi:10.5194/bg-10513-2013, 2013.

Peters, W., Miller, J. B., Whitaker, J., Denning, A. S., Hirsch, A., Krol, M. C., Zupanski, D., Bruhwiler, L., and Tans, P. P.: An ensemble data assimilation system to estimate $\mathrm{CO}_{2}$ surface fluxes from atmospheric trace gas observations, J. Geophys. Res., 110, D24304, doi:10.1029/2005JD006157, 2005.

Piao, S. L., Fang, J. Y., Ciais, P., Peylin, P., Huang, Y., Sitch, S., and Wang, T.: The carbon balance of terrestrial ecosystems in China, Nature, 458, 1009-1013, doi:10.1038/nature07944, 2009.

Rayner, P. J., Enting, I. G., Francey, R. J., and Langenfelds, R.: Reconstructing the recent carbon cycle from atmospheric $\mathrm{CO}_{2},{ }^{13} \mathrm{C}$ and $\mathrm{O}_{2} / \mathrm{N}_{2}$ observations, Tellus, 51B, 213-232, 1999.

Russel, G. and Lerner, J.: A new finite-differencing scheme for the tracer transport equation, J. Appl. Meteorol., 20, 1483-1498, 1981.

Sawa, Y., Machida, T., and Matsueda, H.: Seasonal variations of $\mathrm{CO}_{2}$ near the tropopause observed by commercial aircraft, J. Geophys. Res., 113, D23301, doi:10.1029/2008JD010568, 2008.

Schuck, T. J., Brenninkmeijer, C. A. M., Slemr, F., Xueref-Remy, I., and Zahn, A.: Greenhouse gas analysis of air samples collected onboard the CARIBIC passenger aircraft, Atmos. Meas. Tech., 2, 449-464, doi:10.5194/amt-2-449-2009, 2009.
Stephens, B. B., Gurney, K. R., Tans, P. P., Sweeney, C., Peters, W., Bruhwiler, L., Ciais, P., Ramonet, M., Bousquet, P., Nakazawa, T., Aoki, S., Machida, T., Inoue, G., Vinnichenko, N., Lloyd, J., Jordan, A., Heimann, M., Shibistova, O., Langenfelds, R. L., Steele, L. P., Francey, R. J., and Denning, A. S.: Weak northern and strong tropical land carbon uptake from vertical profiles of atmospheric $\mathrm{CO}_{2}$, Science, 316, 1732-1735, doi:10.1126/science.1137004, 2007.

Tian, H., Melillo, J., Lu, C. Q., Kicklighter, D., Liu, M. L., Ren, W., Xu, X. F., Chen, G. S., Zhang, C., Pan, S. F., Liu, J. Y., and Running, S.: China's terrestrial carbon balance: Contributions from multiple global change factors, Global Biogeochem. Cy., 25, GB1007, doi:10.1029/2010GB003838, 2011.

Tiedtke, M.: A comprehensive mass flux scheme for cumulus parameterisation in large scale models, Mon. Weather Rev., 177, 1779-1800, 1989.

van der Werf, G. R., Randerson, J. T., Giglio, L., Collatz, G. J., Mu, M., Kasibhatla, P. S., Morton, D. C., DeFries, R. S., Jin, Y., and van Leeuwen, T. T.: Global fire emissions and the contribution of deforestation, savanna, forest, agricultural, and peat fires (19972009), Atmos. Chem. Phys., 10, 11707-11735, doi:10.5194/acp10-11707-2010, 2010.

Xueref-Remy, I., Messager, C., Filippi, D., Pastel, M., Nedelec, P., Ramonet, M., Paris, J. D., and Ciais, P.: Variability and budget of $\mathrm{CO}_{2}$ in Europe: analysis of the CAATER airborne campaigns - Part 1: Observed variability, Atmos. Chem. Phys., 11, 56555672, doi:10.5194/acp-11-5655-2011, 2011.

Yan, J. H., Zhang, Y. P., Yu, G. R., Zhou, G. Y., Zhang, L. M., Li, K., Tan, Z. H., and Sha, L. Q.: Seasonal and inter-annual variations in net ecosystem exchange of two old-growth forests in southern China, Agr. Forest Meteorol., 182-183, 257-265, doi:10.1016/j.agrformet.2013.03.002, 2013.

Yuan, W., Luo, Y., Richardson, A. D., Oren, R., Luyssaert, S., Janssens, I. A., Ceulemans, R., Zhou, X., Grünwald, T., Aubinet, M., Berhofer, C., Baldocchi, D. D., Chen, J., Dunn, A. L., Deforest, J. L., Dragoni, D., Goldstein, A. H., Moors, E., William Munger, J., Monson, R. K., Suyker, A. E., Starr, G., Scott, R. L., Tenhunen, J., Verma, S. B., Vesala, T., and Wofsy, S. C.: Latitudinal patterns of magnitude and interannual variability in net ecosystem exchange regulated by biological and environmental variables, Glob. Change Biol., 15, 2905-2920, doi:10.1111/j.1365-2486.2009.01870.x, 2009.

Zhu, W. Q., Pan, Y. Z., Yang, X. Q., and Song, G. B.: Comprehensive analysis of the impact of climatic changes on Chinese terrestrial net primary productivity, Chinese Sci. Bull., 52, 3253-3260, 2007. 